\title{
Chronic Stress Alters Astrocyte Morphology in Mouse Prefrontal Cortex
}

\author{
Sierra A. Codeluppi,Dipashree Chatterjee, Thomas D. Prevot, ${ }^{\circ}$ \\ Yashika Bansal, Keith A. Misquitta, Etienne Sibille, Mounira Banasr
}

Campbell Family Mental Health Research Institute, Centre for Addiction and Mental Health (CAMH), Toronto, Canada (Ms Codeluppi, Ms Chatterjee, Dr Prevot, Dr Bansal, Mr Misquitta, Dr Sibille, and Dr Banasr); Department of Pharmacology and Toxicology (Ms Codeluppi, Ms Chatterjee, Mr Misquitta, Dr Sibille, and Dr Banasr), and Department of Psychiatry (Drs Prevot, Sibille, and Banasr), University of Toronto, Toronto, Canada.

Correspondence: Mounira Banasr, PhD, CAMH, 250 College Street, Toronto, ON M5T 1R8, Canada (Mounira.banasr@camh.ca).

\begin{abstract}
Background: Neuromorphological changes are consistently reported in the prefrontal cortex of patients with stress-related disorders and in rodent stress models, but the effects of stress on astrocyte morphology and the potential link to behavioral deficits are relatively unknown.

Methods: To answer these questions, transgenic mice expressing green fluorescent protein (GFP) under the glial fibrillary acid protein (GFAP) promotor were subjected to 7, 21, or 35 days of chronic restraint stress (CRS). CRS-induced behavioral effects on anhedonia- and anxiety-like behaviors were measured using the sucrose intake and the PhenoTyper tests, respectively. Prefrontal cortex GFP+ or GFAP+ cell morphology was assessed using Sholl analysis, and associations with behavior were determined using correlation analysis.

Results: CRS-exposed male and female mice displayed anxiety-like behavior at 7, 21, and 35 days and anhedonia-like behavior at 35 days. Analysis of GFAP+ cell morphology revealed significant atrophy of distal processes following 21 and 35 days of CRS. CRS induced similar decreases in intersections at distal radii for GFP+ cells accompanied by increased proximal processes. In males, the number of intersections at the most distal radius step significantly correlated with anhedonia-like behavior $(r=0.622, P<.05)$ for GFP+ cells and with behavioral emotionality calculated by $z$-scoring all behavioral measured deficits $(r=-0.667, P<.05)$. Similar but not significant correlations were observed in females. No correlation between GFP cell atrophy with anxiety-like behavior was found.

Conclusion: Chronic stress exposure induces a progressive atrophy of cortical astroglial cells, potentially contributing to maladaptive neuroplastic and behavioral changes associated with stress-related disorders.
\end{abstract}

Keywords: Astroglia, cell morphology, chronic stress, prefrontal cortex, sholl analysis

\section{Introduction}

Allostatic response plays a significant role in an organism's ability to cope with stressful life events by meeting the environmental challenge demands and return to a homeostatic state (Radley et al., 2015; McEwen and Akil, 2020). However, following repeated stress exposure, the increase in allostatic load and the homeostatic state can no longer be maintained. 


\section{Significance Statement}

Astrocytes are brain cells pivotal to the normal function and support of neurons. Clinical and preclinical studies have consistently shown astroglial anomalies in depression and chronic stress rodent models. Here, we demonstrate that chronic stress in mice induces atrophy of the prefrontal cortex astrocytes. We also found that these morphological changes correlate with the behavioral deficits associated with chronic stress. Altogether, our results strongly suggest that stress-induced morphological reorganization of astrocytes and atrophy may contribute in part to the behavioral deficits induced by chronic stress. This work further highlights the contribution of astroglial pathology in stress-related disorders, including depression.

This is associated with maladaptive responses within limbic brain regions, linked with several CNS stress-related disorders, including major depressive disorder (MDD) (McEwen, 1998; Popoli et al., 2011; Radley et al., 2015; McEwen and Akil, 2020). One particular brain region, the prefrontal cortex (PFC), is important in the top-down control of stress response and has been implicated in cognition and emotion regulation (Radley et al., 2015). The PFC undergoes various neuroplastic changes in response to chronic stress exposure that include morphological reorganization such as altered dendrite arborization, dendrites retraction, and synaptic loss (Radley et al., 2004; McEwen and Akil, 2020). These effects are reversible when stress exposure is interrupted (Radley and Morrison, 2005), but if chronic stress persists, it can lead to morphological changes similar to those observed in MDD. These changes include PFC volume reductions (Sheline, 2003; Li et al., 2010; Salvadore et al., 2011) and reduced size of PFC neurons and glial cell numbers (Cotter et al., 2001; Rajkowska and Stockmeier, 2013). Several brain imaging studies have reported that patients with MDD showed volumetric changes in the PFC (Drevets et al., 2008; Nakano et al., 2014; Scheinost et al., 2018). Although neuronal loss with MDD is controversial (Cotter et al., 2002), studies have consistently reported astroglial loss (Rajkowska et al., 2013; Sanacora and Banasr, 2013) and reduced synapse number and synaptic markers (Duric et al., 2010; Kang et al., 2012; Banasr et al., 2021).

Astroglia cells make up approximately $40 \%$ of the cells in the human brain and are numerous in the PFC (Verkhratsky et al., 2017). Astrocyte morphology is classically described as a star-like cell structure with the center being the soma and distinctive long processes that protrude outward. Each of these processes display smaller branching processes of varying lengths and sizes (Matias et al., 2019). Astrocytes are crucial for proper function and CNS plasticity since they are important regulators of synaptic connectivity, synaptogenesis, and maintenance of synaptic function. In addition to providing energy, nutrients, and trophic factors to neurons as well as contributing to recycling neurotransmitters, astrocytes contribute to the fabrication and maintenance of the extracellular matrix responsible for synapse morphology (Bass et al., 1971; Sherwood et al., 2006; Roberts et al., 2014; Peteri et al., 2019; Siracusa et al., 2019).

Astroglia are likely key mediators in the synaptic dysfunction implicated in multiple pathologies of mood disorders (Elsayed and Magistretti, 2015; Rial et al., 2015; Takahashi et al., 2015; Hussaini and Jang, 2018; Peterson and Binder, 2019; Zhou et al., 2019; Fullana et al., 2020). Post-mortem and preclinical studies consistently report reduced density and number of glial fibrillary acid protein (GFAP)+ astroglial cells (Miguel-Hidalgo et al., 2010; Sanacora and Banasr, 2013). Studies also reported decreased GFAP protein and mRNA levels in key brain regions of patients with mood disorders (Miguel-Hidalgo et al., 2010; Nagy et al., 2015), reductions of GFAP+ cells in the PFC of MDD patients (Rajkowska and Stockmeier, 2013), and reductions of various specific markers of astroglial cell function (Nagy et al., 2015). In rodent models of chronic stress, fewer GFAP+ cells are reported in the hippocampus (Czeh et al., 2006), amygdala, and subregions of the PFC (Sanacora and Banasr, 2013). Previous work from our group demonstrated that animals subjected to chronic stress showed reduced levels of GFAP mRNA expression, fewer GFAP+ cells in the prelimbic cortex, and reduced glial metabolism in the PFC (Banasr and Duman, 2008; Banasr et al., 2010). Interestingly, these changes appear selective to $\mathrm{GFAP}+$ astroglia since cortical $\mathrm{S} 100 \beta+$ cell density remains unaffected (Gosselin et al., 2009), suggesting that GFAP+ astroglia population is especially susceptible to chronic stress. Cortical GFAP+ astroglia reduction was directly involved in the expression of depressive-like behaviors. Indeed, we previously demonstrated that local infusion of a gliotoxin producing ablation of GFAP+ cells in the PFC induced anxiety- and anhedonia-like deficits similar to those seen following chronic stress (Banasr and Duman, 2008). Similar PFC astroglia ablation impairs cognitive flexibility (Brockett et al., 2018), promotes ethanol intake (Miguel-Hidalgo et al., 2009), and prevents the antidepressant action of deep brain stimulation (Etievant et al., 2015).

Despite numerous studies identifying reduced astroglial density, little is known about the effects of chronic stress on astroglial morphology in the PFC. In this study, we aimed to conduct comprehensive analyses of chronic stress effects on PFC GFAP+ astroglial morphology using the chronic restraint stress (CRS) model and Sholl analysis (Cook and Wellman, 2004; Radley and Morrison, 2005; Liston et al., 2006; Hercher et al., 2009; Bailey et al., 2012; Maurer et al., 2020). We first assessed the behavioral consequences of 7,21 , or 35 days of CRS in transgenic mice expressing green fluorescent protein (GFP) under the GFAP promotor. We then conducted a Sholl analysis on GFAP astroglia immunolabelled with either GFAP (primarily staining major processes) or GFP (allowing staining of additional small processes). In the investigation of neuronal cell morphology, Sholl analysis and the quantification of the number of intersections is the classical method used to assess branching complexity (Sholl, 1953). Since neuronal morphology is relatively homogeneous within a brain region, this method is well suited for studying the morphological complexity of neurons. Several studies have attempted to apply the same principles to astrocytes (Gzielo et al., 2017; Tavares et al., 2017) but were unable to detect chronic stress effects (Chan et al., 2018), most likely because astrocytes are highly heterogeneous in size and wildly different in morphology (Sofroniew and Vinters, 2010; Jha et al., 2018). In this study, our goal was to adapt the Sholl analysis method to astrocytes and assess astroglial morphology after stress and potential correlation with behavioral deficits. 


\section{METHODS}

\section{Animals}

Animals were housed under normal conditions with an artificial 12-hour-light/-dark cycle and ad libitum access to food and water (except when deprived for testing). All animals were single housed starting the week before the beginning of the stress experiments for individual monitoring of behavioral assessments. All procedures and experiments followed guidelines of the Canadian Council on Animal Care and were approved by Centre for Addiction and Mental Health (CAMH) Animal Care Committee. We used FVB/ $\mathrm{N}-\mathrm{Tg}$ (GFAPGFP)14Mes/J transgenic mice (Jackson Laboratories, stock \#003257) backcrossed with wild-type (WT) C57BL/6 mice for at least 7 generations. Heterozygous GFAP-GFP mice $(n=32)$ were 8-16 weeks of age at the beginning of the experiment.

\section{Chronic Restraint Stress}

Four groups ( $n=8 /$ group, $50 \%$ females) were used in this study, that is, $n=4 /$ sex/group (Figure 1A): the control group (CRS 0) and animals were subjected to 7 (CRS 7), 21 (CRS 21), or 35 days of CRS (CRS 35). During CRS, animals were placed in Falcon Tubes with holes at the bottom and the cap to allow for air flow, 1 hour, twice per day (2 hours apart) between 11:00 AM to 4:00 PM. Control animals were handled daily. Similar CRS procedures were previously used to assess effects of chronic stress on neuronal morphology (da Silva Torres et al., 2003; Imbe et al., 2013; Huang et al., 2019).

\section{Longitudinal Behavioral Assessments}

To assess the progression of chronic stress, animals were tested at the behavioral level weekly, including assessment of coat state, sucrose intake, and time spent in the shelter during the PhenoTyper test (Figure 1A). The experimenter was blinded to the experimental group assignments.

\section{Coat State Assessment}

Coat state assessment was performed as described by Yalcin et al. (2005). Each week at 18 hours after the restraint stress session, 7 body parts were assessed for coat quality (i.e., the head, neck, dorsal coat, ventral coat, tail, forepaws, and hind paws). Each body part was given a score of $0,0.5$, or 1 from well-kept to unkempt. The sum of all scores determined the deterioration score of the animal's coat state.

\section{Sucrose Consumption Test}

During the first week, animals were habituated for 48 hours to $1 \%$ sucrose solution. After habituation, mice were fluid deprived for 16 hours overnight followed by 1 hour of the sucrose consumption test. After the sucrose consumption test, animals were returned to tap water for 24 hours. After 24 hours, animals were deprived of water for 16 hours and then, water intake was measured for 1 hour. Every following week, the animals were only re-habituated to sucrose for 24 hours before the test. Sucrose and water consumption tests were performed each week 18 hours after the restraint stress session.

\section{PhenoTyper Test}

The PhenoTyper test is a consistent and reliable test that measure conflict anxiety-like behavior in mice (Maluach et al., 2017; Nikolova et al., 2018; Prevot et al., 2019). The test uses the
PhenoTyper (Noldus, Leesburg, VA, USA) apparatus, a $30-\mathrm{cm}^{2}$ home cage-like arena with a designated shelter zone and food zone. Each week, animals are placed in the PhenoTyper (minimum of 3 hours after the restraint session and recorded during their dark cycle [7:00 PM to 7:00 AM]). A spotlight placed above the food zone is programmed to turn on at 23:00 for 1 hour. The light challenge causes mice to hide in the shelter zone, behavior exacerbated by chronic stress (Prevot et al., 2019). The continued avoidance of the food zone in favor of shelter is calculated for each animal as the time spent in the shelter zone for the 5 hours after the light challenge (from $12 \mathrm{Am}$ to $5 \mathrm{AM}$ ).

\section{Z-Emotionality Score}

We used an integrative $z$-scoring method to assess the consistency of behavior across tests and compiled behavioral readouts into 1 score of behavioral emotionality for each animal. The z-behavioral emotionality score is calculated as a function of the $\mathrm{SD}$ and average of the control group for each sex and as an average of performances of all behavioral tests (Guilloux et al., 2011).

\section{Mouse Euthanasia and Perfusion}

Animals were anesthetized 20 hours after the last stressor with avertin (125 mg/kg, i.p.) and perfused intracardially with $4 \%$ paraformaldehyde using a Pharmacia pump (ColeParmer, Montreal, Canada). Brains were post-fixed in $4 \%$ paraformaldehyde overnight at $4^{\circ} \mathrm{C}$, cryoprotected in a $30 \% \mathrm{su}$ crose solution ( 48 hours at $4^{\circ} \mathrm{C}$ ), and frozen on dry ice before being stored at $-80^{\circ} \mathrm{C}$. Using a cryostat (Leica CM1950, Buffalo Grove, IL, USA), 40- $\mu \mathrm{m}$-thick sections containing the PFC region (anterioposteriority 2.3-1.4 mm from Bregma) were cut and placed in cryoprotectant $(30 \%$ sucrose, $1 \%$ polyvinylpyrrolidone- $40,30 \%$ ethylene glycol) for storage at $-20^{\circ} \mathrm{C}$.

\section{Immunohistochemistry}

Free-floating sections were washed in $0.3 \%$ phosphate buffer saline (PBS)-TritonX (PBS-T), then incubated with $3 \% \mathrm{H}_{2} \mathrm{O}_{2}$ in PBS for 20 minutes at room temperature. Sections were then incubated for 1 hour in 10\% normal donkey serum in PBS-T, then with primary antibodies (diluted in 3\% normal donkey serum PBS-T) for 48 hours $\left(4^{\circ} \mathrm{C}\right)$. Sections were then washed with PBS and incubated in the secondary antibodies for 2 hours at room temperature. A subset of sections was used to first validate the GFAP-GFP line, that is, verify GFP expression in GFAP+ astrocytes by double labelling for GFP (chicken anti-GFP, Aves GFP-1020, Davis, CA, USA followed by secondary donkey $\alpha$-chicken AF488 antibody, Jackson Immuno Research 703-545-155, West Grove, PA, USA) and antibodies against other cell types. The antibodies used were either the rabbit anti-GFAP antibody (Dako Z0334, Santa Clara, CA, USA) followed by secondary antibody (donkey anti-rabbit DyLight405, Jackson Immuno Research 711-475-152), the ionized calcium binding adaptor molecule 1 (Iba1, microglial marker, rabbit antiIba1, Wako 019-19741, Richmond, VA, USA) followed by donkey anti-rabbit DyLight405 (Jackson Immuno Research 711-475-152), or neuron nuclei protein marker (NeuN, neuronal marker, guinea pig anti-NeuN, EMD Millipore ABN90, ON, Canada) followed by donkey anti-guinea pig (CF405M, Biotium 20376, Fremont, CA, USA).

\section{Acquisition and Quantification}

Using a confocal microscope (Olympus, Bethlehem, PA, USA) with oil-based $100 \times$ objective, 6 GFAP+ and 6 GFP+ cells selected 


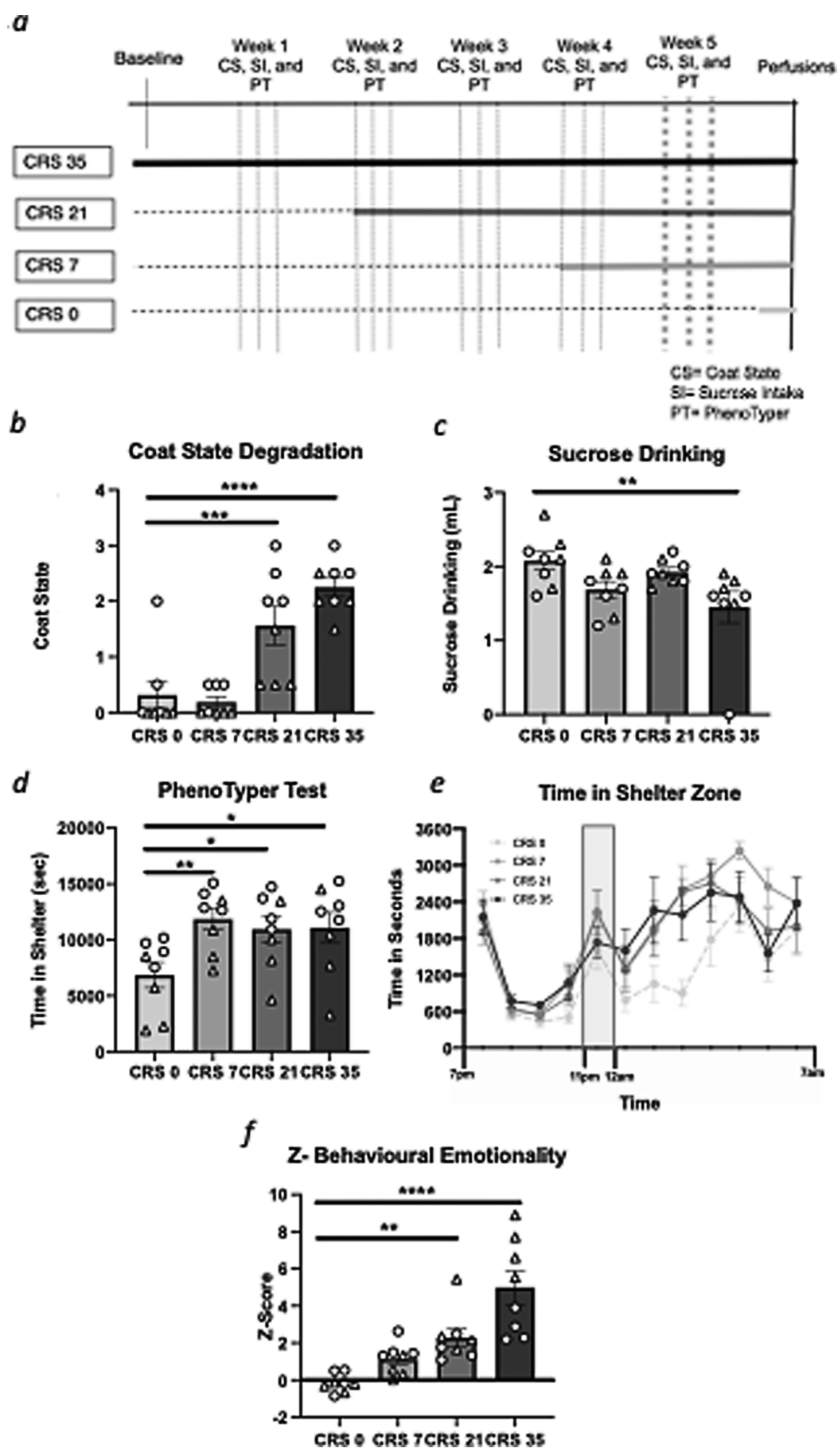

Figure 1. Chronic restraint stress (CRS) effects on behavioral emotionality at experimental week 5. (A) Timeline of CRS and behavioral testing. Behavioral performances measured throughout the chronic stress exposure can be found in supplementary Materials; this figure only illustrates the results obtained on week 5 . CRS increases coat state degradation (B) and reduces sucrose intake (C). In the PhenoTyper test, CRS increased time in the shelter measured either for 5 hours after the light challenge (D) or hourly (E). CRS increased the overall z-score of behavioral emotionality (F). All data presented as mean $\pm \mathrm{SEM}$. ${ }^{*} \mathrm{P}<.05$, ${ }^{* *} \mathrm{P}<.01,{ }^{* * *} \mathrm{P}<.001$, and ${ }^{* * * *} \mathrm{P}<.0001 \mathrm{compared}$ with control group. Females are denoted with a triangle and males with a circle.

from the gray matter, specifically from the anterior cingulate cortex region of the PFC of each mouse, were imaged. To ensure the accurate Sholl analysis measurements, only nonoverlapping immuno-positive cells were selected. The Z-axis diameter for each cell was determined by identifying the upper and lower Z-plane, and the middle of the astrocyte was set as Z0. The FluoView software (FV10-ASW 4.0b) was used to image 5 (GFAP+ cells) or 3 (GFP+ cells) z-stacks equally spanning Z0 (z-step $=5 \mu \mathrm{m}$ or $10 \mu \mathrm{m}$, respectively). The z-steps for each cell type were optimized based on pilot acquisition and quantification trials for each staining. When using z-stacks of smaller intervals, we found that the astrocyte morphology was not quantifiable and did not allow for distinguishing individual processes. The 5 (GFAP+ cells) or 3 (GFP+ cells) z-stacks were projected on a bidimensional image on which the Sholl analysis was performed using ImageJ's plug-in FIJI (Bethesda, MD, USA) 

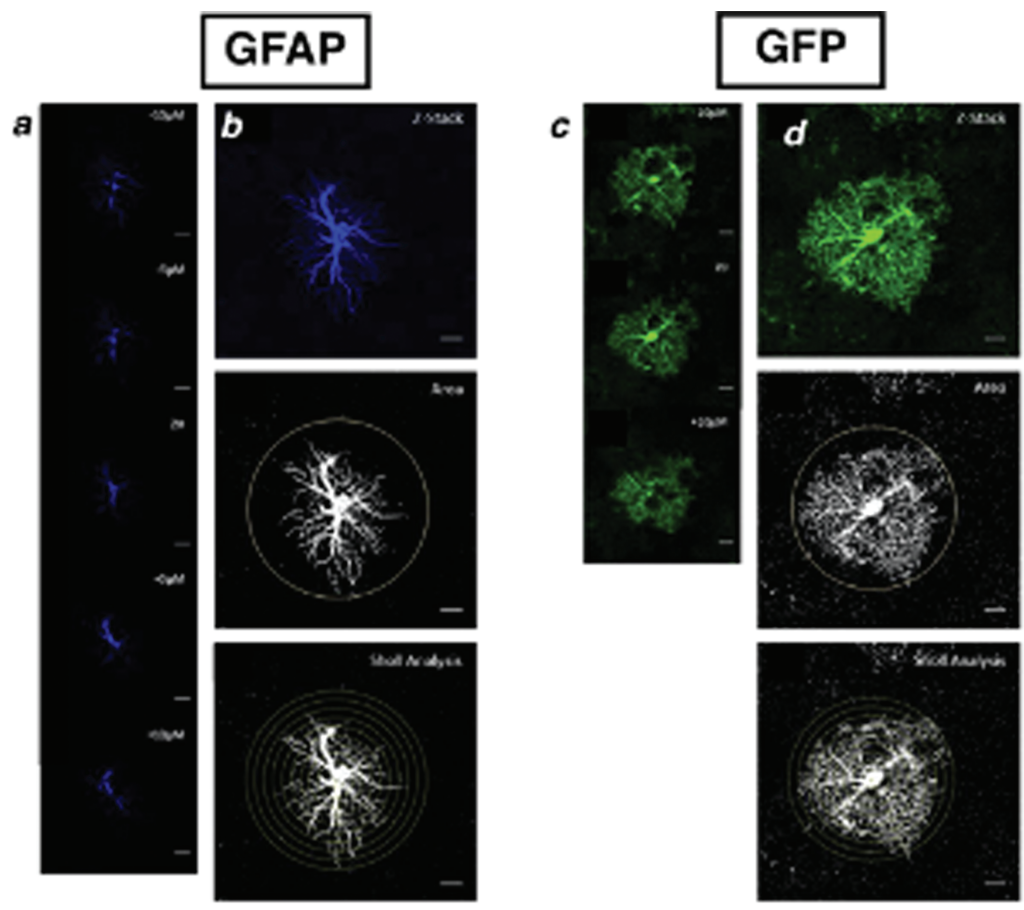

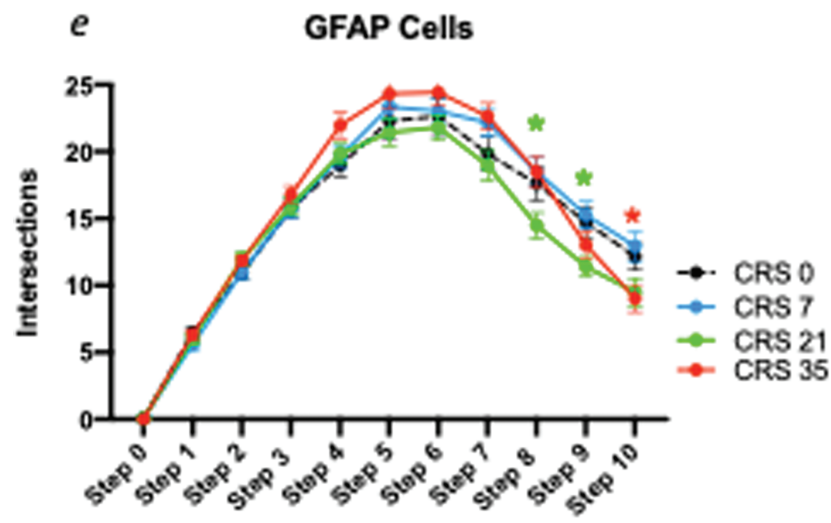

Radius Step

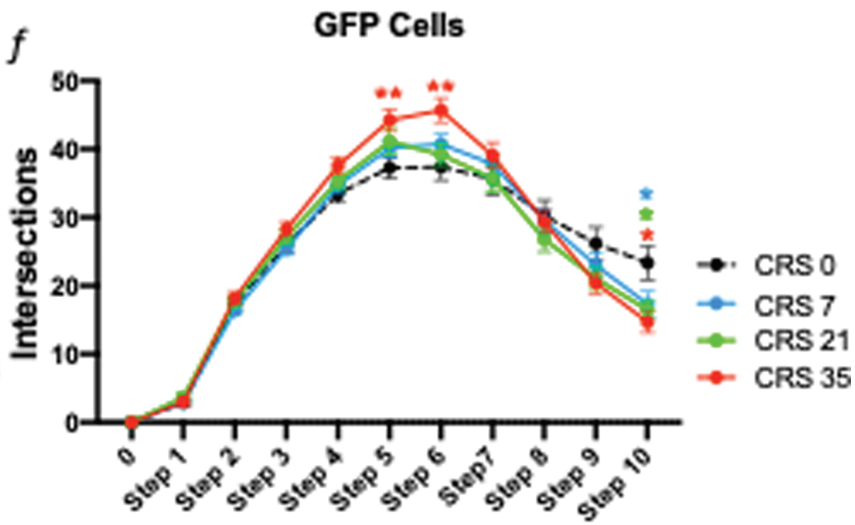

Radius Step

Figure 2. Chronic restraint stress (CRS) alters cortical astrocyte morphology. Scale $=10 \mu \mathrm{m}$. Representative astrocyte stained for glial fibrillary acidic protein (GFAP; blue) (A, B, E) or green fluorescent protein (GFP; green) (C, D, F). Each GFAP-stained cell is imaged over a span of $20 \mu \mathrm{m}$, every $5 \mu \mathrm{m}$, with the middle of the cell = Z0 (A). For each GFAP cell, images are z-stacked (B), thresholded, and Sholl circles placed for analysis with the farthest circle placed at the end of the longest process. Each GFP-stained cell is imaged over a span of $20 \mu \mathrm{m}$, every $10 \mu \mathrm{m}$, with the middle of the cell=ZO (C). For each GFP cell, images are $\mathrm{z}$-stacked, thresholded, and Sholl circles placed for analysis with the farthest circle placed at the end of the longest process (D). CRS alters the number of intersections per radius step of GFAP+ cells (E) and GFP+ cells (F). Data presented as mean \pm SEM. ${ }^{*} P<.05$ and ${ }^{* *} P<.01$ compared with control group.

(Schindelin et al., 2012) and resulting images were converted to 8-bit, optimized for brightness-contrast before thresholding to minimize background noise (Figure 2A-F). Images were then processed with a median filter (FIJI: despeckle function), which replaces each pixel with the median value in its $3 \times 3$ neighborhood removing any salt and pepper noise classically found after thresholding (supplementary Figure S4A-B).

We first used the classical Sholl analysis methods with fixed radius steps of 5 or $10 \mu \mathrm{m}$ as well as other parameters such as longest process, optical density over area, and total number of intersections (see supplementary Material for details). For the adapted Sholl analysis, the longest process of each GFAP+ and GFP+ cell was considered as the furthest Sholl circle (determined automatically in FIJI). Radius step was calculated as radius length divided by 11 , obtaining a set number of 10 radius steps per cell (from 0 to 10). The number of intersections per radius step was defined as number of times processes cross each delineated circle and measured automatically.

\section{Statistical Analysis}

For all behavioral data, ANOVA was used to determine the main effects of stress or sex for 1-time readouts and repeatedmeasures ANOVA to identify potential interactions with time for the collected longitudinal data, followed by Fisher's posthoc test using StatView software 5.0 (Berkley, CA, USA). For the Sholl analysis, power analysis performed on a previous published study (Naskar and Chattarji, 2019) studying the effects of stress on amygdala and hippocampal astrocytes revealed that a minimum of 164 cells would be sufficient to detect an effect 
size of 0.3 , with a 0.9 power and 0.05 probability. In our study, we quantified 6 astrocytes per marker per animal per group (192 cells). Repeated-measures ANOVA was used to analyze the number of intersections per radius step. Finally, the potential relationship between the complexity of cell morphology and behavior was determined using correlation analysis (Pearson's $\mathrm{R}$ Test, Prism 8 Software, San Diego, CA, USA).

\section{RESULTS}

\section{CRS Mice Exhibit Poor Coat State and Anhedonia- and Anxiety-Like Behaviors}

Mice were exposed to $0,7,21$, or 35 days of CRS and coat state, sucrose consumption, and residual avoidance were measured weekly (Figure 1A). Weekly performances are reported in supplementary Material and Figures 1 and 2. Here, we present the data obtained in the last week of behavioral testing.

Analysis of coat state degradation scores revealed a significant main effect of stress $\left(F_{(3,28)}=18.349, P<.0001\right)$. Mice subjected to 21 and 35 days of CRS had significantly increased coat state degradation compared with control mice $(P<.001$ and $P<.0001$, respectively) (Figure 1B). Statistical differences between each group are reported in supplementary Table 1 . When sex was included as a factor, there was a main effect of $\operatorname{sex}\left(F_{(1,28)}=22.059\right.$, $P<.0001$; males have a higher overall score of coat state degradation than the females at baseline) but no sex*stress interaction (supplementary Table 1).

We found a significant main effect of stress on sucrose intake $\left(F_{(3,28)}=3.952, P<.05\right)$. Comparison between groups revealed significant sucrose intake reduction between mice exposed to 35 days of $C R S$ compared with controls $(P<.01)$ (Figure $1 C)$, with no difference in water consumption between groups (CRS0: $1.4 \pm 0.2$; CRS7: $1.9 \pm 0.1$; CRS21: $1.7 \pm 0.2$; CRS35: $1.3 \pm 0.3$ ). No significant effect of sex $\left(F_{(1,2)}=3.01, P=.10\right)$ or a sex*stress interaction $\left(F_{(3,28)}=0.994, P=.412\right)$ was found on sucrose intake (supplementary Table 1).

Analysis of the time spent in the shelter zone calculated for 5 hours after the light challenge showed a significant stress effect $\left(F_{(3,28)}=3.662, P<.01\right)$. Post-hoc analysis revealed a significant increase in time spent in the shelter zone in all stress groups compared with the controls $(P<.01$ for CRS 7 and $P<.05$ for CRS 21 and 35) (Figure 1D). There was a significant main effect of sex $\left(F_{(1,28)}=16.775, P<.001\right)$, with males spending more time in the shelter than females at baseline, but no stress*sex interaction (supplementary Table 1). When looking at the hourly record of the animals' time in the shelter zone, we found a significant main effect of time $\left(F_{(3,12)}=24.269, P<.0001\right)$ and stress $\left(F_{(3,27)}=3.757, P<.05\right)$, but no significant interaction of stress over time $\left(F_{(3,36)}=0.979, P=.508\right)$ (Figure $1 E$ ).

When considering Z-emotionality scores, we found a significant stress effect $\left(\mathrm{F}_{(3.28)}=16.451, \mathrm{P}<.0001\right)$ explained by a significant increase in the CRS 7, CRS 21, and CRS 35 groups compared with the controls $(P<.01, P<.0001)$ (Figure $1 F$; supplementary Table 1). When sex was considered as a factor, a significant main effect of sex $\left(F_{(1,28)}=9.380, P<.01\right)$ and a group*sex interaction $\left(F_{(3,28)}=13.136, P>.0001\right)$ were found. Females showed a greater increase in $z$-behavioral emotionality scores than males in response to chronic stress exposure (supplementary Table 1).

\section{Verification of the GFAP-GFP Transgenic Mouse Line}

Fluorescence immunohistochemistry and confocal analysis was performed on PFC sections from GFAP-GFP heterozygous mice to determine if GFP+ cells of this mouse line were co-labelled with NeuN, Iba1, or GFAP staining. We found no overlap between GFP+ and NeuN+ cell populations. Similarly, GFP+ and Iba1+ cells represented 2 distinct cell types with no overlapping immunostaining. We qualitatively found that a vast majority of the GFP+ cells were GFAP co-labeled, validating the mouse line specificity. We decided to use both markers in our assessment of cell morphology as GFAP immunohistochemistry allows for staining of primary processes while GFP allows for detection of smaller processes (supplementary Figure 3).

\section{CRS Decreased the Number of Intersections at Distal Radius Steps, Suggesting Atrophy of GFAP+ and GFP+ Cells}

We began our morphological analysis by immunolabelling and imaging sections from the PFC with labelled GFAP+ or GFP+ cells. We then thresholded the images for Sholl analysis as seen in Figure 2A-F. We were then able to analyze astrocytes using the classical Sholl technique with a fixed radius step of 5 or $10 \mu \mathrm{m}$ (supplementary Figure 4C-E), longest process (supplementary Figure 4H-I), optical density over area (supplementary Figure $4 \mathrm{~J}-\mathrm{K}$ ), and total intersection numbers (supplementary Figure $4 \mathrm{~L}-\mathrm{M})$. The results indicate no significant effect of CRS or sex (see supplementary Material for details).

As astrocyte size and morphology heterogeneity may be a confounding factor when using the classical Sholl analysis, we adapted the method to quantify intersections per radius step (fixed number of radius steps=11). For GFAP+ cells, there was a significant main effect of stress and radius step $\left(F_{(30,1880)}=2.468\right.$, $\left.P<.0001 ; F_{(3,10)}=379.990, P<.0001\right)$ (Figure 2E). The number of intersections for GFAP+ cells were significantly different at steps 8,9 , and 10. Specifically, significant reductions in the number of intersections were found between CRSO and CRS21 at steps 8 and 9 as well as between CRS 0 and CRS35 at step $10(P<.05)$ (Figure 2E). For GFP+ cells, there was also a significant main effect of stress and radius step $\left(F_{(30,1580)}=2.984, P<.0001 ; F_{(3,10)}=534.843\right.$, $\mathrm{P}<.0001$ ) (Figure $2 \mathrm{~F}$ ). The number of intersections for GFP+ cells was significantly different between groups at steps 5, 6, and 10. Specifically, CRS35 groups significantly increased at steps 5 and 6 and significantly decreased at step 10 compared with CRSO. Similar reductions between CRSO and CRS7 or CRS21 at step 10 were found $(P<.05)$ (Figure $2 F)$. In summary, at step 10, both GFAP+ and GFP+ cells showed reduced numbers of intersections $\left(F_{(3,188)}=3.506, P<.05 ; F_{(3,158)}=3.682, P<.05\right)$ (Figure $\left.3 A-B\right)$. ANOVA performed at this step radius also revealed a significant main effect of sex for GFP+ $\left(\mathrm{F}_{(1,158)}=4.099, \mathrm{P}<.05\right)$ greater number of intersection in females compared with males) but not GFAP+ cells $\left(F_{(1,188)}=0.001, P=.9840\right)$. For both cell types at this radius step, no group*sex interaction was found $\left(F_{(3,188)}=0.693, P=.655\right.$; $\left.F_{(1,158)}=1.599, P=.192\right)$ (supplementary Table 1 ).

\section{CRS-Induced Reduction in Number of Intersections at Distal Radius Steps Correlates With Anhedonia- Like Behavior and z-Behavioral Emotionality Scores}

Potential correlations between anhedonia-like behavior (sucrose intake) or anxiety-like behavior (shelter time) and altered astrocyte morphology were then investigated. We found no correlation between radius step 10 intersections and sucrose intake $(r=0.233, P=.200$; Figure $4 \mathrm{~A})$ or time in the shelter $(r=0.107, P=.559$, Figure $4 C)$ for GFAP+ cells. No correlation was found when the analysis was performed separately for males (sucrose intake: $r=0.357, P=.175$; time in shelter: $r=-0.159$, 
$a$

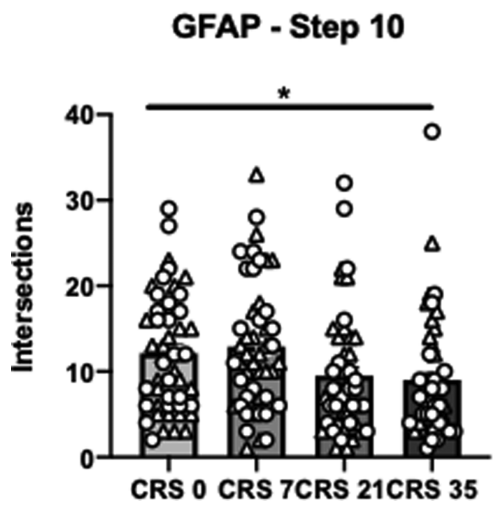

$b$

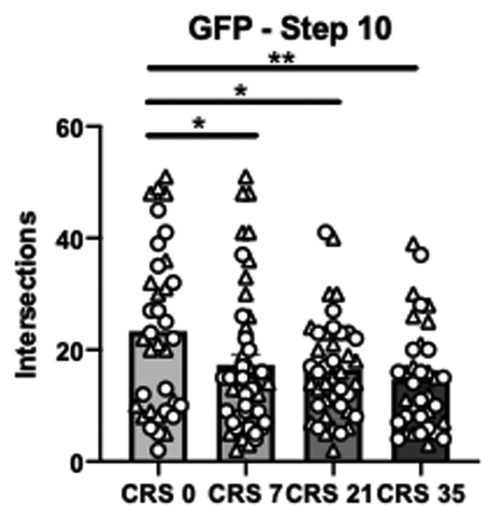

Figure 3. Chronic restraint stress (CRS) alters cortical astrocyte morphology at radius step 10. (A) CRS reduces the number of glial fibrillary acidic protein (GFAP) cell distal intersections at radius step 10. (B) CRS reduces the number of green fluorescent protein (GFP) cells distal intersections at radius step 10. Data presented as mean \pm SEM. ${ }^{*} \mathrm{P}<.05$ and ${ }^{* *} \mathrm{P}<.01$ compared with control group. Females are denoted with a triangle and males with a circle.

$P=.556$ ) and females (sucrose intake: $r=0.003, P=.992$; time in shelter: $r=0.410, P=.115)$. There was a positive correlation between radius step 10 intersections and sucrose intake for GFP+ cells $(r=0.489, P<.01$; Figure $4 \mathrm{~B})$. This positive correlation with GFP+ cells was also significant when data were analyzed separately for males $(r=0.622, P<.05)$ and marginally significant for females $(r=0.547, P=.053)$. In addition, there was no significant correlation between the number of intersections at step 10 and time spent in the shelter for GFP+ cells overall $(r=-0.248, P=.212$, Figure 4D) and in females $(r=-0.253, P=.344)$. However, there was a trend towards a significant negative correlation in male mice $(r=-0.517, P=.070)$. Finally, there was a trend towards a significant negative correlation between $z$-emotionality score and number of intersections at step 10 for GFP+ $(r=-0.341, P=.08$; Figure 4F) but not for GFAP+ cells $(r=-0.257, P=.156$; Figure 4E). In GFP+ cells, male mice showed a significant negative correlation between number of intersections at radius step 10 and z-emotionality score $(r=-0.667, P<.05)$ but not female mice $(r=-0.340, P=.235)$. GFAP+ intersections at radius step 10 did not correlate with $z$-emotionality in males $(r=-0.411, P=.114)$ or females $(r=-0.235, P=.344)$. Due to the discrete changes in astrocyte morphology, the significant correlations between number of intersections and behavioral performances did not survive correction for multiple comparisons. However, we found similar correlation levels at radius step 9 (supplementary Figure 5).

\section{DISCUSSION}

In this study, we investigated the astroglial morphological changes induced by CRS in the mouse PFC. We first confirmed that CRS-exposed mice displayed anxiety- and anhedonia-like behaviors. Indeed, CRS-exposed mice showed increased time spent in the shelter zone in the Phenotyper test after 7, 21, and 35 days of CRS. CRS also induced anhedonia-like behavior, that is, decreased sucrose intake following 35 days of CRS. When considering the average Z-behavioral emotionality score of all behavioral tests, CRS increased behavioral emotionality following 21 and 35 days of CRS. At the cellular level, we improved on current methods of Sholl analysis to account for intrinsic heterogeneity of astrocyte size (Jha et al., 2018) and found that CRS reduced the number of intersections at distal radius steps of GFAP+ cells following 21 and 35 days of exposure. Similar CRSinduced decreases in intersections at distal radii for GFP+ cells were found, accompanied by increased proximal processes, suggesting atrophy of the GFAP+ and GFP+ cells. For PFC GFP+ cells, distal process intersection reductions correlated with sucrose intake (in both males and females) but not with time spent in the shelter zone. Interestingly, for GFP+ cells, the reductions in the distal intersections trended towards a negative correlation with greater z-emotionality, an effect not seen in GFAP+ cells. GFP+ cell atrophy was more pronounced and significantly negatively correlated with z-score in male mice. Altogether, our results showed alterations of astrocyte morphology linked to the behavioral response to CRS. This suggests that morphological reorganization of astrocytes and atrophy may contribute to the behavioral deficits induced by chronic stress.

The CRS paradigm is a well-documented rodent model of chronic stress that was shown to alter the physical animal's state and produce behavioral deficits, including anxiety- and anhedonia-like behaviors (Christiansen et al., 2011; Naert et al., 2011; Chiba et al., 2012; Chu et al., 2016; Fee et al., 2020). Here, we confirmed previous findings from our laboratory and others demonstrating greater coat state deterioration (Nikolova et al., 2018; Prevot et al., 2019), reduction in sucrose intake (Fee et al., 2020), and increase in time spent in the shelter zone after the light challenge in the PhenoTyper test following CRS (Prevot et al., 2019). Importantly, we opted for the use of the CRS paradigm instead of the chronic unpredictable (mild) stress model, which employs milder, randomized, and variable stressors, presuming that CRS would be ideal for a time course study as it would allow for detection of more distinct behavioral and cellular differences between groups with increasing exposure to stress (McLaughlin et al., 2007; Chu et al., 2016). In addition, the CRS paradigm was widely used to examine neuronal morphology changes in the PFC, hippocampus, and amygdala (Cook and Wellman, 2004; Vyas and Chattarji, 2004; McLaughlin et al., 2007; Goldwater et al., 2009; Duman and Duman, 2015; Radley et al., 2015).

The majority of studies investigating neuronal morphology classically use the Sholl analysis, which consists of placing concentric circle (or spheres) on 2-D images (or 3-D images) of neurons, extending from the soma to the tip of the apical dendrite. Each circle is placed at equal distance, that is, fixed radius step size (commonly $10-20 \mu \mathrm{m}$ ), constant regardless of the cell size (Bailey et al., 2012). The apical dendrite length is often selected as a scalar value of complexity to be employed in follow-up correlative analysis within an experiment (Plagemann et al., 1998; McLaughlin et al., 2007; Bailey et al., 2012). This approach has been extensively and successfully used to report the neuronal morphological alterations associated with chronic 


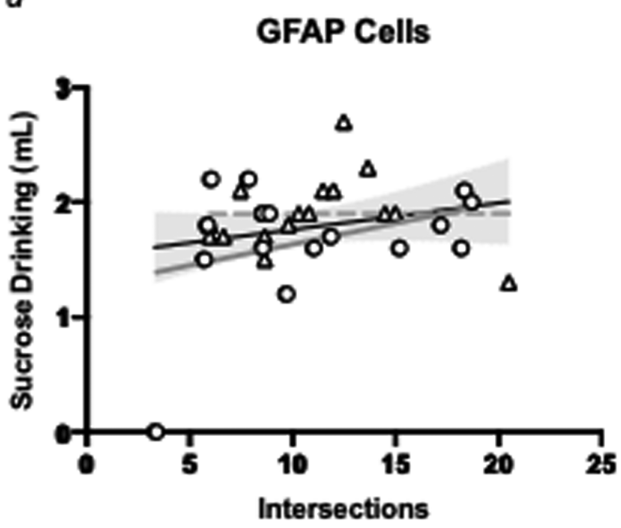

c

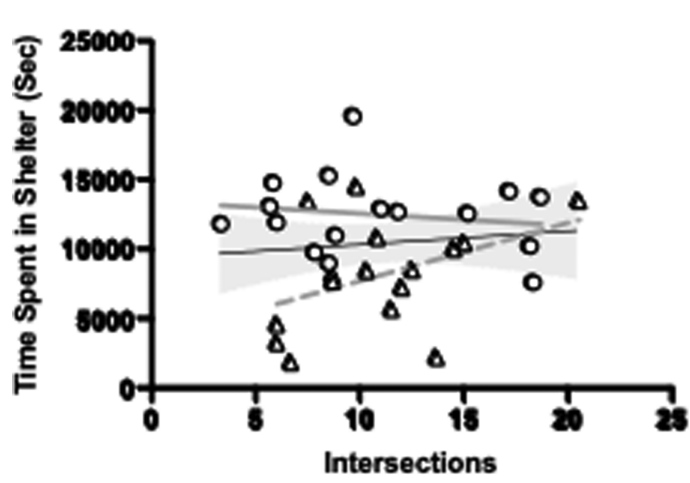

e

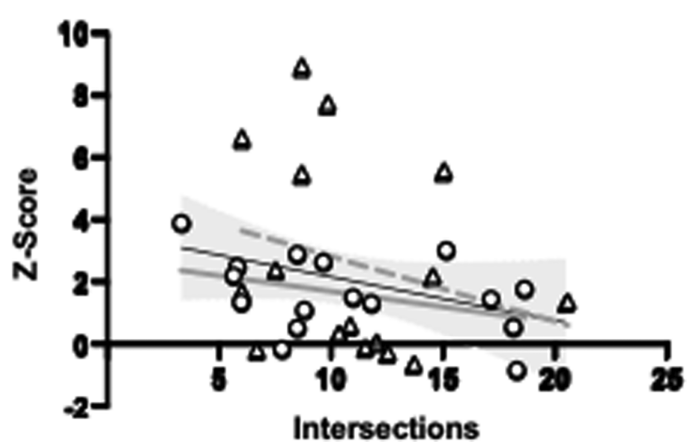

$b$ GFP Cells

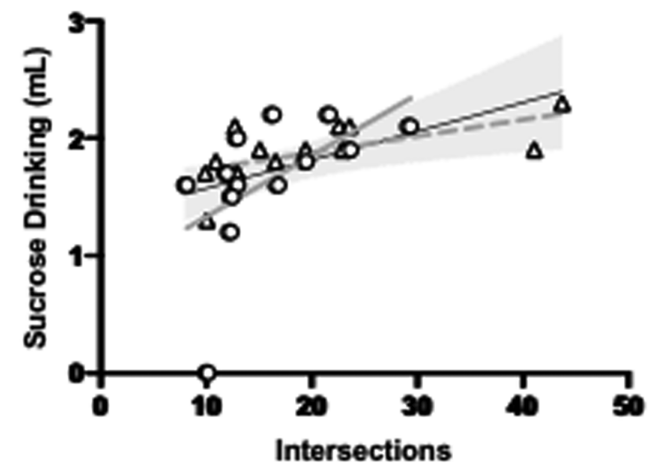

d

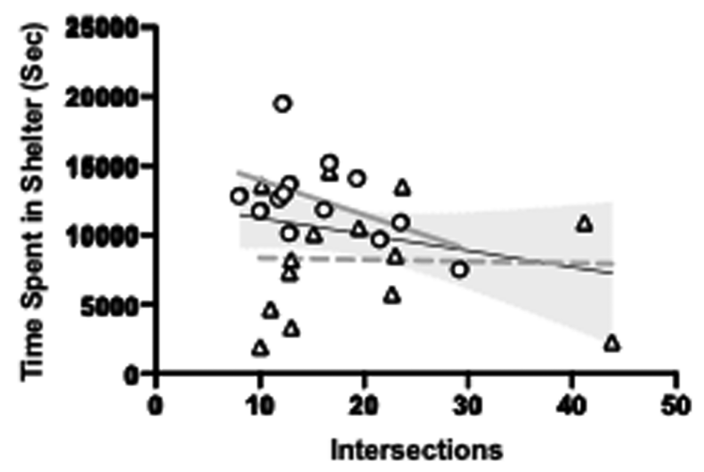

f

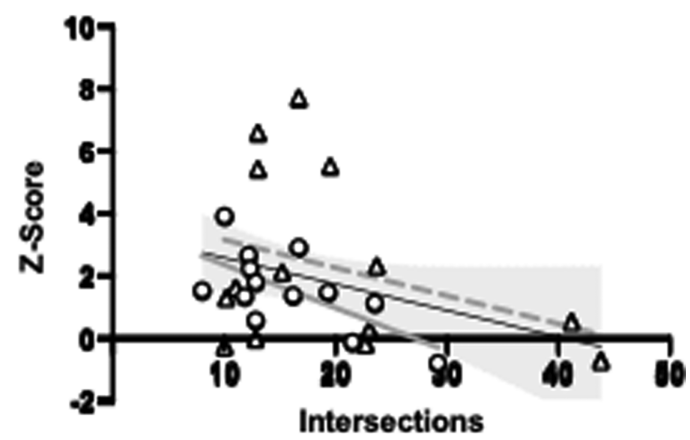

Figure 4. Chronic restraint stress (CRS)-induced alterations in cortical astrocyte morphology correlates with behavioral performances. The average number of intersections at step 10 for each animal calculated for glial fibrillary acidic protein (GFAP) (A, C, E) or green fluorescent protein (GFP) positive cells (B, D, F) (supplementary Figure 4). Relationships between GFAP-cell intersections at step 10 and sucrose intake (A), time spent in the shelter (C), and z-score behavioral emotionality (E) were assessed using Pearson's correlational analysis. Overall regression lines are black. Females are denoted with a triangle, with grey dotted regression lines and males with a circle, with grey bolded regression lines. (A) Overall: $r=0.099, P=.517$; females: $r=0.003, P=.992$; males: $r=0.357, P=.175$. (C) Overall: $r=0.107, P=.559$; females: $r=0.410, P=.115$; males: $r=-0.159, P=.175$. (E) Overall: $r=-0.257, P=.156$. females: $r=-0.253, P=.344$; males: $r=-0.411, P=.114$. A similar analysis was performed for GFP-cell intersections at radius step 10 and sucrose intake (B), time spent in the shelter zone (D), and $z$-score behavioral emotionality (F). (B) Overall: $r=0.489, P<.01$; females: $r=0.622, P<.05$; males: $r=-0.547, P=.053$. (D) Overall: $r=-0.248, P=.212$; females: $r=-0.032, P=.914$; males: $r=-0.517, P=.070$. (F) Overall: $r=-0.341, P=.082$; females: $r=-0.340, P=.235$; males: $r=-0.667, P=.013$. Grey area represents $95 \%$ confidence intervals.

stress (Vyas et al., 2002; McLaughlin et al., 2007; McEwen et al., 2016). We began our investigation by applying these parameters to analyze GFAP+ and GFP+ cell morphology but were unable to detect differences between groups. In this scenario, the use of a fixed-radius step, with a final Sholl circle placed at the same distance for small or larger astrocyte of similar complexity, would skew the data as the smaller astrocyte would artificially display no quantifiable intersections at the farthest
Sholl circle (supplementary Figure 6). This highlights the need to adapt the Sholl analysis method to astrocytes to account for the size heterogeneity of this cell population (Jha et al., 2018). Investigators have attempted to address these methodological challenges using parameters such as cell perimeter (Matsutani and Yamamoto, 1997), soma size, or volume. Chan et al. (2018) investigated CRS effects on GFAP+ soma size and volume but were unable to find significant changes on either parameter. 
Other alternate methods were used to complement the Sholl analysis to address differences in morphological complexity of astrocytes. For example, Johnson et al., (2008) employed a parallel qualitative manual estimation to separate the cells into complexity groups; however, the complexity assessment was subjective, even if the analysis was performed by a blinded experimenter (Johnson et al., 2008). In the present study, to ensure that the distance between Sholl circles was dependent on the size of the cell and that equivalent samples were quantified for each astrocyte, we incorporated cell size in the analysis by using a set number of radius steps. The results of this method unveiled reductions of intersection number at the distal Sholl circles in mice subjected to CRS whether the cell was GFAP or GFP positive. GFP+ cells of CRS animals also showed an increase in number of intersections at the proximal Sholl circles. These data demonstrate reorganization of astrocyte morphology following CRS and suggest distal process atrophy along with preservation of processes closer to the soma. Distal process loss was marked at radius step 10 for both GFAP+ and GFP+ cells. CRS effects on astrocyte morphology appeared earlier and of greater magnitude when quantifying GFP+ cells. This may not be surprising since CRS may affect fine astrocytic processes first (GFP stained processes) and primary (GFAP stained) processes later. Ultimately, we adapted the Sholl analysis to allow for a more refined assessment of astrocyte morphology and demonstrated an atrophy of astrocyte distal processes following CRS.

To establish a relationship between behavior and PFC astrocyte morphology, we investigated whether intersections at distal radius step 10 correlated with anhedonia- and anxietylike behaviors. We found that greater astrocyte atrophy at this radius step positively correlated with greater anhedonia-like behavior, but only trended with greater anxiety-like behavior. These correlations were more pronounced in males. Overall, we also demonstrated a link between GFP+ cell morphology and Z-behavioral emotionality score, suggesting that PFC astrocyte alterations following CRS contribute to behavioral emotionality. Our findings are consistent with the data of the literature showing that chronic stress reduced PFC astrocyte numbers or function (Si et al., 2004; Banasr et al., 2010) and that ablation or dysfunction of these cells induces depressive-like behaviors (Banasr and Duman, 2008; Fullana et al., 2020; Illes et al., 2020). Similar astrocytic loss and dysfunction were also reported in other brain regions and were involved in the expression of emotion-related deficits (Czeh et al., 2006; Gosselin et al., 2009; Radley et al., 2015). In addition, a recent study demonstrated that astroglial morphology is altered in specific subfields of the hippocampal formation following chronic mild unpredictable stress; however, no correlation with behavioral outcomes was performed (Virmani et al., 2021). These additional effects of chronic stress on astrocytic loss or dysfunction as well as the involvement of astrocytic changes in others brain regions may account for additional astroglial contribution to behavioral emotionality.

The chronic stress-induced PFC astroglia atrophy identified in this study may supplement the already well-established neuroplastic changes associated with chronic stress (Radley et al., 2015; McEwen and Akil, 2020) or MDD (Kang et al., 2012; Lin and Sibille, 2015; Scheinost et al., 2018; Banasr et al., 2021). It is possible that the same mechanisms involved in the chronic stress-induced neuronal atrophy also alter astrocyte morphology, for example, increased corticosterone (McEwen, 1998; Wellman, 2001), excess extra-synaptic glutamate (Popoli et al., 2011), or decreased trophic support (Duman and Duman, 2015). Astrocytes also play a vital role in the regulation and function of neurons, particularly through the reuptake of extra-synaptic neurotransmitters (Roberts et al., 2014; Peteri et al., 2019; Siracusa et al., 2019; Fullana et al., 2020). Therefore, chronic stress-induced alterations of astrocyte morphology could have direct consequences on the neuronal function and synaptic transmission, exacerbating chronic stress effects on neuronal populations. To investigate this hypothesis further, functional consequences of manipulations mimicking chronic stress effects on astrocyte morphology, activity, or function should be considered. These studies may include investigating activity or cell signaling changes within astrocytes after chronic stress or neurons following astrocyte manipulations (Newman, 2003; Grienberger and Konnerth, 2012; Kim et al., 2015; Perrin-Terrin et al., 2016; Fee et al., 2020).

Although the main focus of this study was investigating the effects of chronic stress exposure on astrocyte morphology, according to current research guidelines, we included an equal number of male and female mice in our study design to account for sex, a basic biological variable. Interestingly, CRS male mice showed greater anxiety- and anhedonia-like behavior as well as increased degradation of coat state when individual behavioral outcomes were considered. However, CRS females showed overall greater Z-emotionality score normalized to controls of the same sex group across behavioral tests. This is consistent with literature suggesting that females are more affected by stress and exhibit more and greater symptoms in stress-related disorders (Kessler et al., 1993). Although we confirmed sex differences in the behavioral response to CRS (Prevot et al., 2019; Fee et al., 2020), we found only some minor sex differences in morphology and were unable to see interaction between sex and groups. This could indicate that chronic stress does not alter astrocyte morphology in a sex-dependent manner or that a considerably greater number of animals per group and per sex are needed to detect sexual dimorphism associated with PFC astrocyte morphology, as previously described in the hypothalamus (Salmaso et al., 2005). Future studies specifically designed for studying sexual dimorphism of astrocyte morphology in PFC would be needed to answer this question. These studies may also need to include estrus cycle stages as an additional variable since this may explain why similar but not significant correlations between PFC astrocyte morphology and behavioral changes were found in males and females.

This study is not without its limitations. First, as mentioned above, we conducted the study on a relatively small number of animals of each sex. Second, we chose to focus on GFAP+ astrocytes and not S100 $\beta+$ cells, as mice exposed to chronic stress show only reductions in GFAP+ cells (Gosselin et al., 2009). We also focused on the PFC as this is the main region consistently showing astroglial changes in cell density in MDD. Findings in other brain regions such as the hippocampus have been inconsistent (Webster et al., 2001; Cobb et al., 2016; Virmani et al., 2021). Finally, this study focused on identifying chronic stress effects on PFC astrocyte morphology; the mechanisms responsible for chronic stress-induced atrophy or the consequences of these changes on neuronal morphology, activity, and function remain to be investigated. Indeed, these astrocytic changes may be linked to the decrease in synapse number and synaptic markers reported in chronic stress models (Radley et al., 2015; Khan et al., 2020) and MDD (Duric et al., 2010; Kang et al., 2012; Rial et al., 2015).

Nevertheless, in this study we demonstrated that chronic stress alters GFAP+ astrocyte morphology in the PFC and may contribute to the chronic stress-associated behavioral deficits. We examined the timeline of these effects and provided a 
quantitative method of analysis of astrocyte complexity. This complements preclinical studies that consistently show reduced density and number of GFAP+ astroglia cells in chronic stress models and findings of astrocyte reduction in MDD, further highlighting the role of astrocytes in stress-related illnesses.

\section{Supplementary Materials}

Supplementary data are available at International Journal of Neuropsychopharmacology (IJNPPY) online.

\section{Acknowledgments}

We thank Colin Arrowsmith for his input on the calculations of astrocyte morphology indexes. We also acknowledge the contributions of the CAMH animal facility personnel for animal care and genotyping services, specifically Lori Dixon, Kristen Fournier, Katrina Deverell, and German Fernandes.

This work was supported by the CAMH discovery fund (M.B., T.P.) and the Canadian Institutes of Health Research (PGT165852, PI: M.B.) and the Campbell Family Mental Health Research Institute. Interest Statement: None.

\section{References}

Bailey CD, Alves NC, Nashmi R, De Biasi M, Lambe EK (2012) Nicotinic $\alpha 5$ subunits drive developmental changes in the activation and morphology of prefrontal cortex layer VI neurons. Biol Psychiatry 71:120-128.

Banasr M, Chowdhury GM, Terwilliger R, Newton SS, Duman RS, Behar KL, Sanacora G (2010) Glial pathology in an animal model of depression: reversal of stress-induced cellular, metabolic and behavioral deficits by the glutamate-modulating drug riluzole. Mol Psychiatry 15:501-511.

Banasr M, Duman RS (2008) Glial loss in the prefrontal cortex is sufficient to induce depressive-like behaviors. Biol Psychiatry 64:863-870.

Banasr M, Sanacora G, Esterlis I (2021) Macro- and microscale stress-associated alterations in brain structure: translational link with depression. Biol Psychiatry 90:118-127.

Bass NH, Hess HH, Pope A, Thalheimer C (1971) Quantitative cytoarchitectonic distribution of neurons, glia, and DNA in rat cerebral cortex. J Comp Neurol 143:481-490.

Brockett AT, Kane GA, Monari PK, Briones BA, Vigneron PA, Barber GA, Bermudez A, Dieffenbach U, Kloth AD, Buschman TJ, Gould E (2018) Evidence supporting a role for astrocytes in the regulation of cognitive flexibility and neuronal oscillations through the $\mathrm{Ca}^{2+}$ binding protein S100ß PLoS One 13:e0195726.

Chan TE, Grossman YS, Bloss EB, Janssen WG, Lou W, McEwen BS, Dumitriu D, Morrison JH (2018) Cell-type specific changes in glial morphology and glucocorticoid expression during stress and aging in the medial prefrontal cortex. Front Aging Neurosci 10:146.

Chiba S, Numakawa T, Ninomiya M, Richards MC, Wakabayashi C, Kunugi H (2012) Chronic restraint stress causes anxiety- and depression-like behaviors, downregulates glucocorticoid receptor expression, and attenuates glutamate release induced by brain-derived neurotrophic factor in the prefrontal cortex. Prog Neuropsychopharmacol Biol Psychiatry 39:112-119.

Christiansen SH, Olesen MV, Wortwein G, Woldbye DP (2011) Fluoxetine reverts chronic restraint stress-induced depressionlike behaviour and increases neuropeptide $\mathrm{Y}$ and galanin expression in mice. Behav Brain Res 216:585-591.
Chu X, Zhou Y, Hu Z, Lou J, Song W, Li J, Liang X, Chen C, Wang S, Yang B, Chen L, Zhang X, Song J, Dong Y, Chen S, He L, Xie Q Chen X, Li W (2016) 24-Hour-restraint stress induces long-term depressive-like phenotypes in mice. Sci Rep 6:32935.

Cobb JA, O'Neill K, Milner J, Mahajan GJ, Lawrence TJ, May WL, Miguel-Hidalgo J, Rajkowska G, Stockmeier CA (2016) Density of GFAP-immunoreactive astrocytes is decreased in left hippocampi in major depressive disorder. Neuroscience 316:209-220.

Cook SC, Wellman CL (2004) Chronic stress alters dendritic morphology in rat medial prefrontal cortex. J Neurobiol 60:236-248.

Cotter D, Mackay D, Chana G, Beasley C, Landau S, Everall IP (2002) Reduced neuronal size and glial cell density in area 9 of the dorsolateral prefrontal cortex in subjects with major depressive disorder. Cereb Cortex 12:386-394.

Cotter DR, Pariante CM, Everall IP (2001) Glial cell abnormalities in major psychiatric disorders: the evidence and implications. Brain Res Bull 55:585-595.

Czeh B, Simon M, Schmelting B, Hiemke C, Fuchs E (2006) Astroglial plasticity in the hippocampus is affected by chronic psychosocial stress and concomitant fluoxetine treatment. Neuropsychopharmacology 31:1616-1626.

da Silva Torres IL, Cucco SN, Bassani M, Duarte MS, Silveira PP, Vasconcellos AP, Tabajara AS, Dantas G, Fontella FU, Dalmaz C, Ferreira MB (2003) Long-lasting delayed hyperalgesia after chronic restraint stress in rats-effect of morphine administration. Neurosci Res 45:277-283.

Drevets WC, Price JL, Furey ML (2008) Brain structural and functional abnormalities in mood disorders: implications for neurocircuitry models of depression. Brain Struct Funct 213:93-118.

Duman CH, Duman RS (2015) Spine synapse remodeling in the pathophysiology and treatment of depression. Neurosci Lett 601:20-29.

Duric V, Banasr M, Licznerski P, Schmidt HD, Stockmeier CA, Simen AA, Newton SS, Duman RS (2010) A negative regulator of MAP kinase causes depressive behavior. Nat Med 16:13281332.

Elsayed M, Magistretti PJ (2015) A new outlook on mental illnesses: glial involvement beyond the glue. Front Cell Neurosci 9:468.

Etievant A, Lucas G, Dkhissi-Benyahya O, Haddjeri N (2015) The role of astroglia in the antidepressant action of deep brain stimulation. Front Cell Neurosci 9:509.

Fee C, Prevot T, Misquitta K, Banasr M, Sibille E (2020) Chronic stress-induced behaviors correlate with exacerbated acute stress-induced cingulate cortex and ventral hippocampus activation. Neuroscience 440:113-129.

Fullana N, Gasull-Camós J, Tarrés-Gatius M, Castañé A, Bortolozzi A,Artigas F (2020) Astrocyte control of glutamatergic activity: downstream effects on serotonergic function and emotional behavior. Neuropharmacology 166:107914.

Goldwater DS, Pavlides C, Hunter RG, Bloss EB, Hof PR, McEwen BS, Morrison JH (2009) Structural and functional alterations to rat medial prefrontal cortex following chronic restraint stress and recovery. Neuroscience 164:798-808.

Gosselin RD, Gibney S, O'Malley D, Dinan TG, Cryan JF (2009) Region specific decrease in glial fibrillary acidic protein immunoreactivity in the brain of a rat model of depression. Neuroscience 159:915-925.

Grienberger C, Konnerth A (2012) Imaging calcium in neurons. Neuron 73:862-885. 
Guilloux JP, Seney M, Edgar N, Sibille E (2011) Integrated behavioral z-scoring increases the sensitivity and reliability of behavioral phenotyping in mice: relevance to emotionality and sex. J Neurosci Methods 197:21-31.

Gzielo K, Kielbinski M, Ploszaj J, Janeczko K, Gazdzinski SP, Setkowicz Z (2017) Long-term consumption of high-fat diet in rats: effects on microglial and astrocytic morphology and neuronal nitric oxide synthase expression. Cell Mol Neurobiol 37:783-789.

Hercher C, Turecki G, Mechawar N (2009) Through the looking glass: examining neuroanatomical evidence for cellular alterations in major depression. J Psychiatr Res 43:947-961.

Huang N, Yang C, Hua D, Li S, Zhan G, Yang N, Luo A, Xu H (2019) Alterations in the BDNF-mTOR signaling pathway in the spinal cord contribute to hyperalgesia in a rodent model of chronic restraint stress. Neuroscience 409:142-151.

Hussaini SMQ, Jang MH (2018) New roles for old glue: astrocyte function in synaptic plasticity and neurological disorders. Int Neurourol J 22:S106-S114.

Illes P, Rubini P, Yin H, Tang Y (2020) Impaired ATP release from brain astrocytes may be a cause of major depression. Neurosci Bull 36:1281-1284.

Imbe H, Kimura A, Donishi T, Kaneoke Y (2013) Effects of restraint stress on glial activity in the rostral ventromedial medulla. Neuroscience 241:10-21.

Jha MK, Kim JH, Song GJ, Lee WH, Lee IK, Lee HW, An SSA, Kim S, Suk K (2018) Functional dissection of astrocyte-secreted proteins: Implications in brain health and diseases. Prog Neurobiol 162:37-69.

Johnson RT, Breedlove SM, Jordan CL (2008) Sex differences and laterality in astrocyte number and complexity in the adult rat medial amygdala. J Comp Neurol 511:599-609.

Kang HJ, Voleti B, Hajszan T, Rajkowska G, Stockmeier CA, Licznerski P, Lepack A, Majik MS, Jeong LS, Banasr M, Son H, Duman RS (2012) Decreased expression of synapse-related genes and loss of synapses in major depressive disorder. Nat Med 18:1413-1417.

Kessler RC, McGonagle KA, Swartz M, Blazer DG, Nelson CB (1993) Sex and depression in the National Comorbidity Survey. I: lifetime prevalence, chronicity and recurrence. J Affect Disord 29:85-96.

Khan AR, Geiger L, Wiborg O, Czéh B (2020) Stress-induced morphological, cellular and molecular changes in the brainlessons learned from the chronic mild stress model of depression. Cells 9:1026.

Kim Y, Venkataraju KU, Pradhan K, Mende C, Taranda J, Turaga SC, Arganda-Carreras I, Ng L, Hawrylycz MJ, Rockland KS, Seung HS, Osten P (2015) Mapping social behavior-induced brain activation at cellular resolution in the mouse. Cell Rep 10:292-305.

Li CT, Lin CP, Chou KH, Chen IY, Hsieh JC, Wu CL, Lin WC, Su TP (2010) Structural and cognitive deficits in remitting and nonremitting recurrent depression: a voxel-based morphometric study. Neuroimage 50:347-356.

Lin LC, Sibille E (2015) Somatostatin, neuronal vulnerability and behavioral emotionality. Mol Psychiatry 20:377-387.

Liston C, Miller MM, Goldwater DS, Radley JJ, Rocher AB, Hof PR, Morrison JH, McEwen BS (2006) Stress-induced alterations in prefrontal cortical dendritic morphology predict selective impairments in perceptual attentional set-shifting. J Neurosci 26:7870-7874.

Maluach AM, Misquitta KA, Prevot TD, Fee C, Sibille E, Banasr M, Andreazza AC (2017) Increased neuronal DNA/RNA oxidation in the frontal cortex of mice subjected to unpredictable chronic mild stress. Chronic Stress 1:2470547017724744.
Matias I, Morgado J, Gomes FCA (2019) Astrocyte heterogeneity: impact to brain aging and disease. Front Aging Neurosci 11:59.

Matsutani S, Yamamoto N (1997) Neuronal regulation of astrocyte morphology in vitro is mediated by GABAergic signaling. Glia 20:1-9.

Maurer J, Yanez A, Bengtson CP, Bading H, Draguhn A, Mauceri D, Both M (2020) VEGF-D downregulation in CA1 pyramidal neurons exerts asymmetric changes of dendritic morphology without correlated electrophysiological alterations. Neuroscience 448:28-42.

McEwen BS (1998) Protective and damaging effects of stress mediators. N Engl J Med 338:171-179.

McEwen BS, Akil H (2020) Revisiting the stress concept: implications for affective disorders. J Neurosci 40:12-21.

McEwen BS, Nasca C, Gray JD (2016) Stress effects on neuronal structure: hippocampus, amygdala, and prefrontal cortex. Neuropsychopharmacology 41:3-23.

McLaughlin KJ, Gomez JL, Baran SE, Conrad CD (2007) The effects of chronic stress on hippocampal morphology and function: an evaluation of chronic restraint paradigms. Brain Res 1161:56-64.

Miguel-Hidalgo J, Shoyama Y, Wanzo V (2009) Infusion of gliotoxins or a gap junction blocker in the prelimbic cortex increases alcohol preference in Wistar rats. J Psychopharmacol 23:550-557.

Miguel-Hidalgo JJ, Waltzer R, Whittom AA, Austin MC, Rajkowska G, Stockmeier CA (2010) Glial and glutamatergic markers in depression, alcoholism, and their comorbidity. J Affect Disord 127:230-240.

Naert G, Ixart G, Maurice T, Tapia-Arancibia L, Givalois L (2011) Brain-derived neurotrophic factor and hypothalamicpituitary-adrenal axis adaptation processes in a depressivelike state induced by chronic restraint stress. Mol Cell Neurosci 46:55-66.

Nagy C, Suderman M, Yang J, Szyf M, Mechawar N, Ernst C, Turecki G (2015) Astrocytic abnormalities and global DNA methylation patterns in depression and suicide. Mol Psychiatry 20:320-328.

Nakano M, Matsuo K, Nakashima M, Matsubara T, Harada K, Egashira K, Masaki H, Takahashi K, Watanabe Y (2014) Gray matter volume and rapid decision-making in major depressive disorder. Prog Neuropsychopharmacol Biol Psychiatry 48:51-56.

Naskar S, Chattarji S (2019) Stress elicits contrasting effects on the structure and number of astrocytes in the amygdala versus hippocampus. eNeuro 6:ENEURO.0338-18.2019.

Newman EA (2003) New roles for astrocytes: regulation of synaptic transmission. Trends Neurosci 26:536-542.

Nikolova YS, Misquitta KA, Rocco BR, Prevot TD, Knodt AR, Ellegood J, Voineskos AN, Lerch JP, Hariri AR, Sibille E, Banasr M (2018) Shifting priorities: highly conserved behavioral and brain network adaptations to chronic stress across species. Transl Psychiatry 8:26.

Perrin-Terrin AS, Jeton F, Pichon A, Frugière A, Richalet JP, Bodineau L, Voituron N (2016) The c-FOS protein immunohistological detection: a useful tool as a marker of central pathways involved in specific physiological responses in vivo and ex vivo. J Vis Exp 110:53613.

Peteri UK, Niukkanen M, Castrén ML (2019) Astrocytes in neuropathologies affecting the frontal cortex. Front Cell Neurosci 13:44.

Peterson AR, Binder DK (2019) Post-translational regulation of GLT-1 in neurological diseases and its potential as an effective therapeutic target. Front Mol Neurosci 12:164. 
Plagemann A, Staudt A, Gotz F, Malz U, Rohde W, Rake A, Dorner G (1998) Long-term effects of early postnatally administered interleukin-1-beta on the hypothalamic-pituitary-adrenal (HPA) axis in rats. Endocr Regul 32:77-85.

Popoli M, Yan Z, McEwen BS, Sanacora G (2011) The stressed synapse: the impact of stress and glucocorticoids on glutamate transmission. Nat Rev Neurosci 13:22-37.

Prevot TD, Misquitta KA, Fee C, Newton DF, Chatterjee D, Nikolova YS, Sibille E, Banasr M (2019) Residual avoidance: a new, consistent and repeatable readout of chronic stressinduced conflict anxiety reversible by antidepressant treatment. Neuropharmacology 153:98-110.

Radley J, Morilak D, Viau V, Campeau S (2015) Chronic stress and brain plasticity: mechanisms underlying adaptive and maladaptive changes and implications for stress-related CNS disorders. Neurosci Biobehav Rev 58:79-91.

Radley JJ, Morrison JH (2005) Repeated stress and structural plasticity in the brain. Ageing Res Rev 4:271-287.

Radley JJ, Sisti HM, Hao J, Rocher AB, McCall T, Hof PR, McEwen BS, Morrison JH (2004) Chronic behavioral stress induces apical dendritic reorganization in pyramidal neurons of the medial prefrontal cortex. Neuroscience 125:1-6.

Rajkowska G, Hughes J, Stockmeier CA, Javier Miguel-Hidalgo J, Maciag D (2013) Coverage of blood vessels by astrocytic endfeet is reduced in major depressive disorder. Biol Psychiatry 73:613-621.

Rajkowska G, Stockmeier CA (2013) Astrocyte pathology in major depressive disorder: insights from human postmortem brain tissue. Curr Drug Targets 14:1225-1236.

Rial D, Lemos C, Pinheiro H, Duarte JM, Gonçalves FQ, Real JI, Prediger RD, Gonçalves N, Gomes CA, Canas PM, Agostinho P, Cunha RA (2015) Depression as a glial-based synaptic dysfunction. Front Cell Neurosci 9:521.

Roberts RC, Roche JK, McCullumsmith RE (2014) Localization of excitatory amino acid transporters EAAT1 and EAAT2 in human postmortem cortex: a light and electron microscopic study. Neuroscience 277:522-540.

Salmaso N, Popeski N, Peronace LA, Woodside B (2005) Differential effects of reproductive and hormonal state on basic fibroblast growth factor and glial fibrillary acid protein immunoreactivity in the hypothalamus and cingulate cortex of female rats. Neuroscience 134:1431-1440.

Salvadore G, Nugent AC, Lemaitre H, Luckenbaugh DA, Tinsley R, Cannon DM, Neumeister A, Zarate CA Jr, Drevets WC (2011) Prefrontal cortical abnormalities in currently depressed versus currently remitted patients with major depressive disorder. Neuroimage 54:2643-2651.

Sanacora G, Banasr M (2013) From pathophysiology to novel antidepressant drugs: glial contributions to the pathology and treatment of mood disorders. Biol Psychiatry 73:1172-1179.

Scheinost D, Holmes SE, DellaGioia N, Schleifer C, Matuskey D, Abdallah CG, Hampson M, Krystal JH, Anticevic A, Esterlis I (2018) Multimodal investigation of network level effects using intrinsic functional connectivity, anatomical covariance, and structure-to-function correlations in unmedicated major depressive disorder. Neuropsychopharmacology 43:1119-1127.

Schindelin J, Arganda-Carreras I, Frise E, Kaynig V, Longair M, Pietzsch T, Preibisch S, Rueden C, Saalfeld S, Schmid B,
Tinevez JY, White DJ, Hartenstein V, Eliceiri K, Tomancak P, Cardona A (2012) Fiji: an open-source platform for biologicalimage analysis. Nat Methods 9:676-682.

Sheline YI (2003) Neuroimaging studies of mood disorder effects on the brain. Biol Psychiatry 54:338-352.

Sherwood CC, Stimpson CD, Raghanti MA, Wildman DE, Uddin M, Grossman LI, Goodman M, Redmond JC, Bonar CJ, Erwin JM, Hof PR (2006) Evolution of increased glia-neuron ratios in the human frontal cortex. Proc Natl Acad Sci U S A 103:13606-13611.

Sholl DA (1953) Dendritic organization in the neurons of the visual and motor cortices of the cat. J Anat 87:387-406.

Si X, Miguel-Hidalgo JJ, O'Dwyer G, Stockmeier CA, Rajkowska G (2004) Age-dependent reductions in the level of glial fibrillary acidic protein in the prefrontal cortex in major depression. Neuropsychopharmacology 29:2088-2096.

Siracusa R, Fusco R, Cuzzocrea S (2019) Astrocytes: role and functions in brain pathologies. Front Pharmacol 10:1114.

Sofroniew MV, Vinters HV (2010) Astrocytes: biology and pathology. Acta Neuropathol 119:7-35.

Takahashi K, Kong Q, Lin Y, Stouffer N, Schulte DA, Lai L, Liu Q, Chang LC, Dominguez S, Xing X, Cuny GD, Hodgetts KJ, Glicksman MA, Lin CL (2015) Restored glial glutamate transporter EAAT2 function as a potential therapeutic approach for Alzheimer's disease. J Exp Med 212:319-332.

Tavares G, Martins M, Correia JS, Sardinha VM, Guerra-Gomes S, das Neves SP, Marques F, Sousa N, Oliveira JF (2017) Employing an open-source tool to assess astrocyte tridimensional structure. Brain Struct Funct 222:1989-1999.

Verkhratsky A, Zorec R, Parpura V (2017) Stratification of astrocytes in healthy and diseased brain. Brain Pathol 27:629644.

Virmani G, D'almeida P, Nandi A, Marathe S (2021) Subfieldspecific effects of chronic mild unpredictable stress on hippocampal astrocytes. Eur J Neurosci.

Vyas A, Chattarji S (2004) Modulation of different states of anxiety-like behavior by chronic stress. Behav Neurosci 118:1450-1454.

Vyas A, Mitra R, Shankaranarayana Rao BS, Chattarji S (2002) Chronic stress induces contrasting patterns of dendritic remodeling in hippocampal and amygdaloid neurons. J Neurosci 22:6810-6818.

Webster MJ, Knable MB, Johnston-Wilson N, Nagata K, Inagaki M, Yolken RH (2001) Immunohistochemical localization of phosphorylated glial fibrillary acidic protein in the prefrontal cortex and hippocampus from patients with schizophrenia, bipolar disorder, and depression. Brain Behav Immun 15:388400.

Wellman CL (2001) Dendritic reorganization in pyramidal neurons in medial prefrontal cortex after chronic corticosterone administration. J Neurobiol 49:245-253.

Yalcin I, Aksu F, Belzung C (2005) Effects of desipramine and tramadol in a chronic mild stress model in mice are altered by yohimbine but not by pindolol. Eur J Pharmacol 514:165174.

Zhou X, Xiao Q, Xie L, Yang F, Wang L, Tu J (2019) Astrocyte, a promising target for mood disorder interventions. Front Mol Neurosci 12:136. 